\title{
Integration of Probabilistic Effectiveness with a Two-stage Genetic Algorithm Methodology to Develop Optimum Maintenance Strategies for Bridges
}

\author{
Elia A. Tantele ${ }^{*}$, Renos A. Votsis and Toula Onoufriou
}

Cyprus University of Technology Saripolou 2-8, Cyprus

\begin{abstract}
Preventative Maintenance (PM) measures can be used to postpone/delay the initiation of corrosion from chloride attack in reinforced concrete bridges. However there are a lot of uncertainties that influence their degree of effectiveness. Also the time-application of these measures can raise a conflict between safety requirements and budgets. This paper presents a stochastic approach for estimating the effectiveness of different PM measures. Additionally a two-stage optimisation methodology using the principles of Genetic Algorithms (GA) is developed to address the problem of the timeapplication by linking the effectiveness with the cost to produce optimum PM strategies. Futhermore, the role of the presented time-dependent probabilistic approach in the proposed two-stage GA methodology for obtaining optimum PM strategies is demonstrated.
\end{abstract}

Keywords: Corrosion initiation, genetic algorithm, Monte Carlo simulation, optimization, preventative maintenance effectiveness, reinforced concrete bridges.

\section{INTRODUCTION}

Maintaining bridges in an acceptable and serviceable condition is an expensive but inevitable task since they represent a valuable asset of the transport network of any country. Typically bridges represent about $2 \%$ of its length and about $30 \%$ of its value [1].

Corrosion of the reinforcing steel is a global problem, causing serious detrimental effects in many types of concrete structures. In particular, chloride-induced corrosion is considered to be the main mechanism of deterioration. The sources of chlorides are usually the seawater and the de-icing salts used to keep the roads free from ice and snow. In order to repair the damages and maintain the long-term performance of such structures, a vast amount of money and a proper maintenance plan are required. The current typical management maintenance strategy is based on a reactive process, i.e. action is taken after deterioration is observed. However, the maintenance cost in such cases is significantly elevated compared to a preventative maintenance approach, resulting in a non-optimum use of the available funding.

To achieve a pro-active bridge management (BM) approach, Preventative Maintenance (PM) measures can be used to maintain a bridge in a serviceable condition by postponing the deterioration process. The effectiveness of different PM measures has been investigated by many researchers, considering either site observations/laboratory tests [2], or the assumed effect that PM measures have on deterioration models $[3,4]$. However, more work is needed to model the effectiveness of specific PM actions on particular deterioration mechanisms.

*Address correspondence to this author at the Cyprus University of Technology Saripolou 2-8, Cyprus; Tel: 0035725002523 ;

E-mail: elia.tantele@cut.ac.cy
Another vital issue is the effective use of the limited maintenance funds. To this effect, it is necessary to develop a methodology that will provide an optimum PM strategy that indicates the time-application of various PM measures while taking into consideration that specific objectives need to be satisfied. In the current study, Genetic Algorithm (GA) principles are utilized to develop such a methodology. The GA, inspired by the Darwinian theory, is an optimization algorithm where the solution is obtained through an evolutionary process that combines nature's mechanisms (e.g. natural selection) with randomized genetic operators, such as crossover and mutation [5-7]. The GAs have been applied in the area of maintenance optimization by other researchers such as Furuta et al. [8], Miyamoto et al. [9], Liu and Frangopol [4] Lee and Kim [10] and Orcesi and Frangopol [11].

The proposed methodology provides an alternative and different approach compared to other GA applications in the maintenance optimization area. The innovation includes the fact that the methodology integrates a probabilistic modelling approach of PM effectiveness with a two-stage GA optimization method. In addition, a multi-objective optimizations problem that combines minimum cost and acceptable probability of failure limits is formulated to produce optimum PM strategies. The ultimate aim of the present study is to provide a tool to determine the effectiveness of PM actions on a predefined deterioration mechanism in a maintenance optimization framework through GA principles. The methodology is developed and demonstrated for a range of different PM measures applied on a typical bridge element (i.e. a reinforced concrete beam) under chloride attack.

\section{PM MEASURES}

\subsection{Probabilistic Analysis Procedure}

The following probabilistic procedure is adopted to enable the prediction of the effectiveness of various PM 
measures under the action of chloride ions, while allowing uncertainties to be incorporated into the chloride ingress model. A bridge structural RC element (e.g. slab, beam etc) under chloride attack is considered for examination. Collepardi et al. [12], were the first to use the Fick's law to model chloride diffusion. Since then, the diffusion of chlorides is widely accepted that can be described by Fick's second law of diffusion (Eq. 1) as:

$C_{(x, t)}=C_{s}\left[1-\operatorname{erf}\left(\frac{x}{2 \sqrt{D_{e} t}}\right)\right]$

where $\mathrm{C}_{(\mathrm{x}, \mathrm{t})}$ is the chloride concentration at depth $\mathrm{x}$ after time $\mathrm{t}\left(\mathrm{kg} / \mathrm{m}^{3}\right) ; \mathrm{C}_{\mathrm{s}}$ is the chloride concentration at the surface $\left(\mathrm{kg} / \mathrm{m}^{3}\right) ; \mathrm{x}$ is the distance from the surface to the reinforcement $(\mathrm{m}) ; \mathrm{D}_{\mathrm{e}}$ is the effective rate of chloride ion diffusion through concrete $\left(\mathrm{m}^{2} / \mathrm{yr}\right) ; \mathrm{t}$ is the time of exposure to surface chlorides (years); and erf $(z)$ is the error function for variable $\mathrm{Z}$.

By applying PM measures at different time intervals, corrosion initiation can be postponed and/or inhibited. As a result, the probability of failure can be maintained within an acceptable target level. In the context of this study, the initiation of corrosion is adopted as the critical failure incident. In particular, failure (i.e. initiation of corrosion) occurs when the concentration of chlorides at the surface of the steel reinforcement exceeds a predefined threshold value. Mathematically, this can be expressed through the following limit state:

$G(x)=C_{t h}-C_{(x, t)}$

where $\mathrm{C}_{\mathrm{th}}$ is the threshold chloride concentration $\left(\mathrm{kg} / \mathrm{m}^{3}\right)$; $\mathrm{C}_{(\mathrm{x}, \mathrm{t})}$ is the chloride concentration at steel reinforcement $\left(\mathrm{kg} / \mathrm{m}^{3}\right)$ calculated using Fick's second law of diffusion and $\mathrm{G}(\mathrm{x})$ is the limit state.

Therefore, the effectiveness of PM measures can be described as a probability of failure through the above mentioned limit state $\mathrm{G}(\mathrm{x})$. Namely:

$p_{f(t)}=p(G(x)<0)=p\left(C_{t h}-C_{(x, t)}<0\right)$

The probability of failure $\left(\mathrm{p}_{\mathrm{f}}\right)$ profiles of various PM measures (as a function of time) are estimated through Monte Carlo simulations [13]. The Crude Monte Carlo simulation method is widely used in modern engineering problems. It involves simulating a large number of numerical experiments and using the results to estimate the probability of failure (pf). Failures are counted depending on the resulting sign of Equation 3. The $\mathrm{p}_{\mathrm{f}}$ is estimated as the ratio of the number of failures to the total number of simulation cycles (Eq. 4) as:

$p_{f(t)}=N_{f}(t) / N(t)$

where $\mathrm{N}_{\mathrm{f}}(\mathrm{t})$ is the number of simulation cycles at a reference time $t$ in which $\mathrm{G}(\mathrm{x})<0 ; \mathrm{N}(\mathrm{t})$ is the total number of simulation cycles at reference time $t$. The statistical accuracy of the estimated $\mathrm{p}_{\mathrm{f}}$ is measured by the coefficient of variation $(\mathrm{CoV})$ as:

$\operatorname{CoV}\left(p_{f}\right) \cong \frac{\sqrt{\frac{\left(1-p_{f}\right) p_{f}}{N}}}{p_{f}}$
The accuracy of the estimated pf is improved as the value of the $\mathrm{CoV}$ is reduced. The effectiveness of various PM measures based on their ability to reduce/inhibit the corrosion initiation is incorporated in the deterioration model and corresponding $\mathrm{p}_{\mathrm{f}}$ profiles can be produced.

\section{EFFECTIVENESS OF PREVENTATIVE MAINTE- NANCE}

It is a difficult task to establish the effectiveness of PM since it depends on a variety of factors (e.g. correct application). An approach can be based on the ability of PM to keep the reinforcement bar (rebar) free from chloride ions. Therefore, for this study PM measures are divided into three categories depending on the effect they have on delaying or ceasing chloride ingress and thus corrosion as depicted in Fig. (1). These categories are discussed in the following sections.

\subsection{Delaying Chloride Ingress}

Surface treatments are decelerating chloride ingress. When surface treatments are applied, the diffusion coefficient $\left(D_{e}\right)$ of the concrete is changed. The new combined diffusion coefficients (surface treated specimen) are derived using Buenfeld and Zhang [14] equation as:

$D_{e}=\frac{T_{c}}{\left(\frac{T_{s t}}{D_{s t}}+\frac{T_{s u}}{D_{s u}}\right)}$

where $\mathrm{T}_{\mathrm{su}}$ is the thickness of the specimen (concrete cover depth); $\mathrm{D}_{\mathrm{su}}$ is the diffusion coefficient of the specimen (concrete); $\mathrm{T}_{\mathrm{st}}$ is the thickness of the surface treatment layer; $\mathrm{D}_{\text {st }}$ is the diffusion coefficient of the surface treatment layer; $\mathrm{T}_{\mathrm{c}}$ is the thickness of the specimen and the surface treatment, which is equal to $T_{s t}+T_{\text {su. }}$. The effectiveness of each surface treatment and thus the $\mathrm{p}_{\mathrm{f}}$ profile of each action depends on the new combined diffusion coefficient $D_{e}$. It must be mentioned that lower values of $\mathrm{D}_{\mathrm{e}}$ indicate a higher effectiveness of the applied measure.

\subsection{Prevent Further Chloride Ingress}

The second category includes measures such as the cathodic protection and the waterproofing membrane.

Cathodic Protection (CP): Prevents further deposition of chloride ions on rebar and removes the existing chloride ions from the rebar's surface, using an electrochemical process. For as long as it is in operation, it excludes the event of initiation of corrosion. It is assumed that it is $100 \%$ effective in keeping the reinforcement bar free from chlorides, i.e. $\mathrm{p}_{\mathrm{f}}$ is zero when CP is in service (Fig. 2a).

Waterproofing System (WS): Capable of preventing the chloride's ingress when it is in perfect condition; otherwise a small degree of chloride ingress may occur mainly due to poor quality workmanship or materials used, A simple modelling approach is adopted here which takes into account the probability of WS failing. The latter is assumed to be $10 \%$. Within the context of this study, waterproofing is considered to be an option when the structure is not corroded, i.e. $\mathrm{p}_{\mathrm{f}}$ (target) is not reached (Fig. 2b).

The effect of CP and WS on the probability of failure can be seen schematically in Fig. (2). 


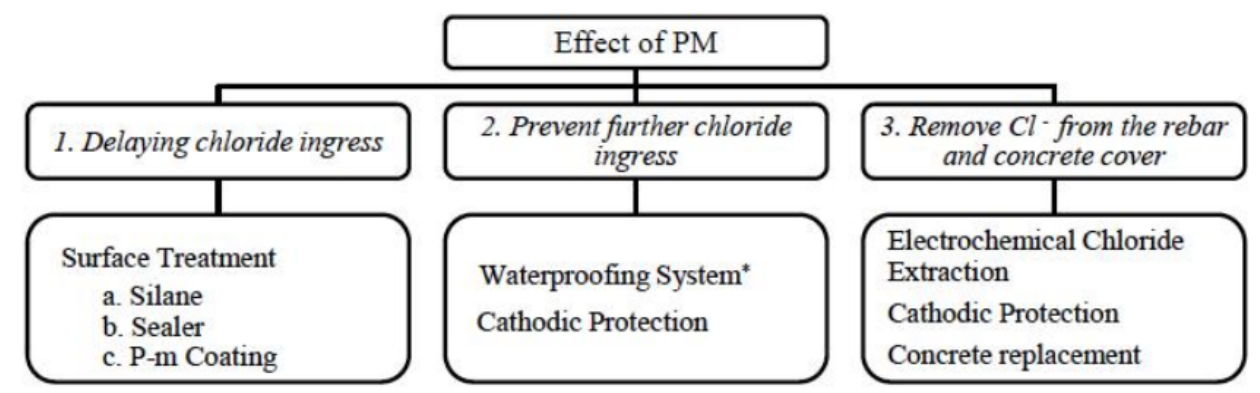

*Assuming waterproofing membrane is in perfect condition.

Fig. (1). Categories of PM measures based on their effect.

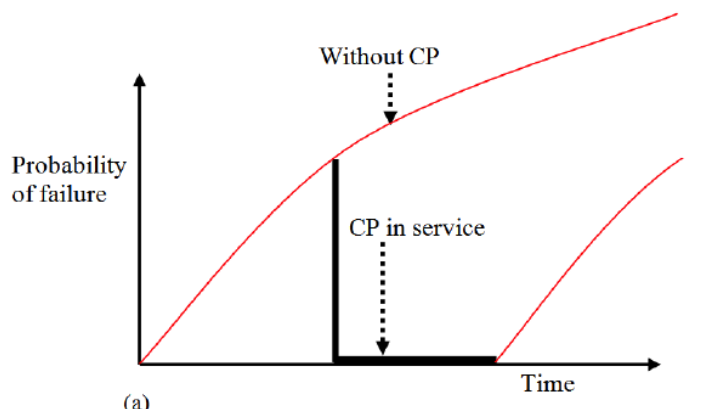

(a)

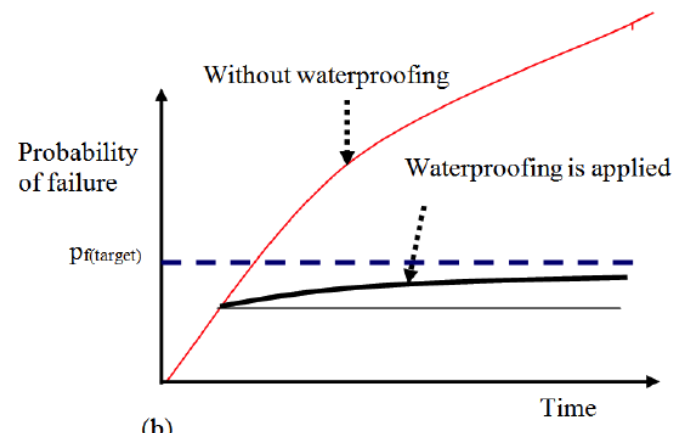

(b)

Fig. (2). Effect of PM measures on the diffusion process (a) CP and (b) WS.

Fig. (2) illustrates that when $\mathrm{CP}$ is applied and as long as it is in operation, the $\mathrm{p}_{\mathrm{f}}$ reduces to zero. For the case of the $\mathrm{WS}$, considering it is in perfect condition, the $\mathrm{p}_{\mathrm{f}}$ should remain constant but due to the probability of the WS failing (i.e., $10 \%$ ), a $\mathrm{p}_{\mathrm{f}}$ profile is assumed.

\subsection{Remove Chlorides from Reinforcement Bar and Concrete Cover}

The third category of PM includes the electrochemical chloride extraction (ECE) and the concrete replacement (CR) methods which both are removing the chlorides.

Electrochemical Chloride Extraction (ECE): Removes a part of the amount of chlorides in the concrete cover. However, a percentage remains in the concrete and chloride ingress continues after the application is completed. The assumed reduction of chlorides due to ECE application is based on studies by Clemena and Jackson [15] and Sharp et al. [16]. Based on these findings it is assumed, that the reduction of chloride concentration throughout the concrete cover is $40 \%$ and this assumption is used to produce the $\mathrm{p}_{\mathrm{f}}$ profile.

Concrete Replacement (CR): The contaminated part of a concrete element that has critical concentration of chlorides can be replaced with a new one. This has to be performed before the initiation of corrosion on the rebar. Therefore, when CR is applied, there is $100 \%$ efficiency in removing the chlorides and thus the $\mathrm{p}_{\mathrm{f}}$ approaches zero.

\section{CASE STUDIES OF PROBABILISTIC MODEL- LING ON EFFECTIVENESS OF PM}

A typical structural element of a RC bridge (beam) subjected to de-icing salts is examined. The first case examines the effect of various surface treatments on the postponement of corrosion. The second case examines the effect of the electrochemical chloride extraction on the $\mathrm{p}_{\mathrm{f}}$ profiles. The combined diffusion coefficients derived (Eq. 6) for the different surface treatments are listed in Table 1 along with the values for plain concrete.

Table 2 lists all the values for the various parameters involved in the probabilistic analysis based on related published work mainly for the UK RC bridges.

It must be noted that the concrete cover, $\mathrm{x}$, in this research study is taken as the effective concrete cover; that is the concrete cover minus the depth of the concrete cover that absorption may occur. Therefore, the chloride ingress is modelled as a Fickian process only over the effective concrete cover depth.

\subsection{Case 1 - Effectiveness of Different Surface Treat- ments}

The selection of appropriate values for the parameters used in the computation of the probability of failure (Eq. 3) is necessary. An investigation of the pertinent literature reveals that there are generally very limited data regarding the effectiveness of PM measures. The parameter values for the combined diffusion coefficient (Eq. 6) adopted in this study, are based on relevant work by Buenfeld and Zhang [14], Krauss et al. [17] and Middleton and Hogg [18] (Table 1). The remaining data for producing the probability of failure profiles are taken from Table 2. While analysing the probability of failure profiles of various PM measures (Fig. 3), it must be emphasized that low $p_{f}$ values mean high reliability and high effectiveness. 
Table 1. Surface treatment parameters $[14,17,18]$.

\begin{tabular}{|c|c|c|c|c|c|c|c|}
\hline PM & Description & $\begin{array}{c}\mathbf{D}_{\mathbf{s t}} \\
\mathbf{m}^{2} / \mathbf{y}\end{array}$ & $\begin{array}{c}\mathbf{T}_{\mathbf{s t}} \\
\mathbf{m m}\end{array}$ & $\begin{array}{c}\mathbf{D}_{\text {su }} \\
\mathbf{m}^{2} / \mathbf{y}\end{array}$ & $\begin{array}{c}\mathbf{T}_{\text {su }} \\
\mathbf{m m}\end{array}$ & $\begin{array}{c}\mathbf{D}_{\mathbf{e}} \\
\mathbf{m}^{2} / \mathbf{y}\end{array}$ & $\begin{array}{c}\mathbf{T}_{\mathbf{c}} \\
\mathbf{m m}\end{array}$ \\
\hline \hline P-m coating & Polymer modified coating & $6.3 \mathrm{E}-15$ & 1.5 & $3.15 \mathrm{E}-5$ & 40 & $4.71 \mathrm{E}-6$ & 41.5 \\
\hline Sealer & Polyurethane Sealer & $1.4 \mathrm{E}-15$ & 0.02 & $3.15 \mathrm{E}-5$ & 40 & $2.32 \mathrm{E}-5$ & 40.02 \\
\hline Penetrant & Silane & $2.5 \mathrm{E}-13$ & $-2^{*}$ & $3.15 \mathrm{E}-5$ & 40 & $2.74 \mathrm{E}-5$ & 38 \\
\hline Control & Concrete with No PM & - & - & $3.15 \mathrm{E}-5$ & 40 & $3.15 \mathrm{E}-5$ & 40 \\
\hline
\end{tabular}

* Depth below the surface of the concrete.

Table 2. Values and distribution type of basic random variables.

\begin{tabular}{|c|c|c|c|c|c|}
\hline $\mathrm{C}_{\mathrm{s}}$ & $\begin{array}{l}\text { Uniform }^{\#} \\
{[1.2-2.4]}\end{array}$ & $3.15 \mathrm{E}-05^{*}$ & & $\mathrm{~kg} / \mathrm{m}^{3}$ & [18] \\
\hline \multirow[b]{2}{*}{$\mathrm{D}_{\mathrm{e}}$} & \multirow[b]{2}{*}{ Normal } & $2.74 \mathrm{E}-05^{* *}$ & \multirow[b]{2}{*}{$0.2^{\# \#}$} & \multirow[b]{2}{*}{$\mathrm{m}^{2 /} \mathrm{yr}$} & \multirow[b]{2}{*}{ [14]; [18] } \\
\hline & & $2.32 \mathrm{E}-05^{* * *}$ & & & \\
\hline $\mathrm{x}$ & Normal & 0.04 & 0.25 & $\mathrm{~m}$ & [19] \\
\hline Cth & [0.6-1.2] & & & $\mathrm{kg} / \mathrm{m}^{3}$ & [20] \\
\hline
\end{tabular}

\#assumed distribution, \#\# assumed CoV based on [18], *Plain concrete, ** Silane, *** Sealer, ****P-m coating

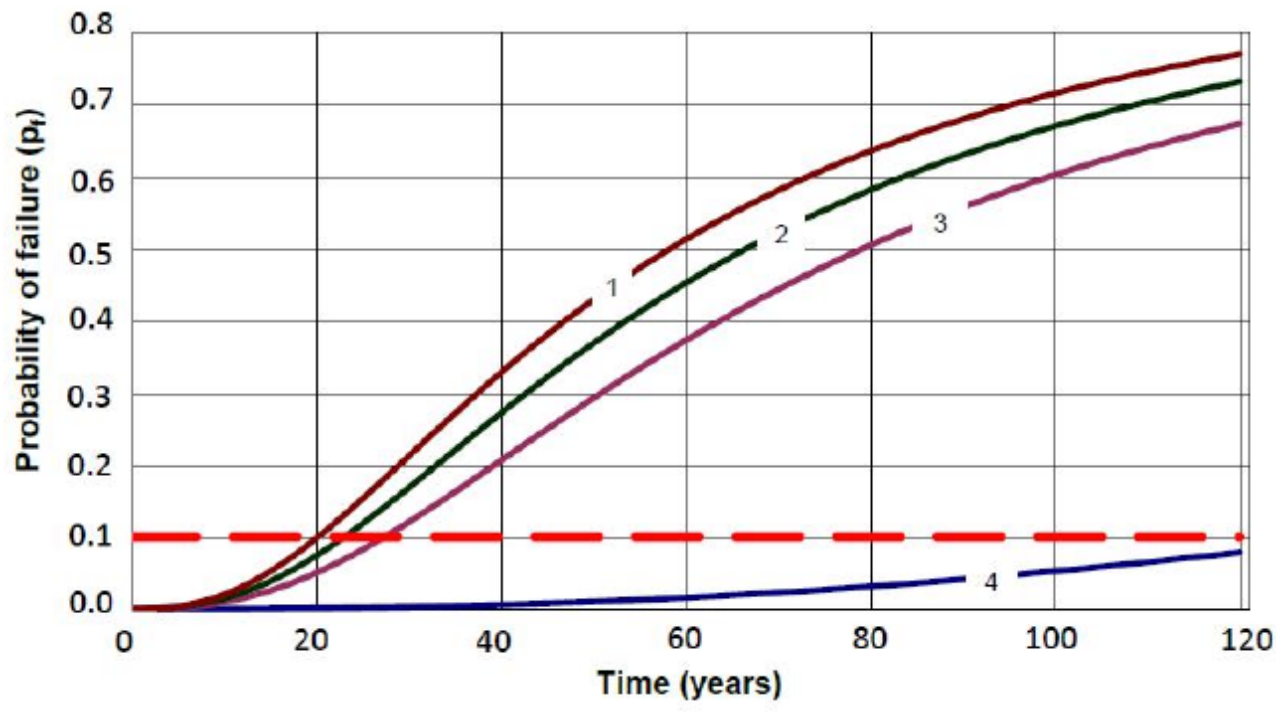

1: Plain concrete, 2: Silane, 3: Polyurethane sealer, 4: P-m coating.

Fig. (3). Surface treatment measures with $40 \mathrm{~mm}$ concrete cover - Probability of failure versus time of exposure.

Three surface treatments (silane, sealer, polymer modified cementitious coating) were selected to represent the categories of surface treatment to protect concrete structures from the diffusion of chloride. The predicted probability of corrosion initiation varied with the application of different surface treatments (i.e., different $D_{e}$ taken from Tables 1 and 2) and it can be seen in Fig. (3). The treated concrete provides more resistance to chloride diffusion than the concrete itself, therefore has more effectiveness. An interesting observation here is that although the diffusion coefficient of P$\mathrm{m}$ coating alone (Dst $\mathrm{p}_{\mathrm{m}}$ ) is higher than the corresponding value for the sealer $\left(\mathrm{Dst}_{\text {sealer }}\right.$ ) the overall diffusion resistance of the former is higher due to its greater thickness.

Fig. (3) shows that corrosion initiation is very likely for a plain concrete element (assumed $\mathrm{p}_{\mathrm{f}} 10 \%$ ) at 20 years of service. The same element when silane and sealer is applied has 
a $10 \%$ probability of corrosion initiation after 22 and 28 years respectively. Last, corrosion of concrete treated with P$\mathrm{m}$ coating is unlikely to occur even after 120 years (bridge expected service life).

\subsection{Case 2 - Electrochemical Chloride Extraction with Different Surface Treatments}

The effectiveness of the electrochemical chloride extraction (ECE) is calculated based on the assumptions made in Section 3.3. Fig. (4) illustrates the reduction of the $p_{f}$ based on the action applied before setting the ECE. For example and with regard to Fig. (4), if an element is deteriorating without any surface treatment ( $\mathrm{p}_{\mathrm{f}}$ profile of control) at time 80 , the $\mathrm{p}_{\mathrm{f}}$ is the value at point $\mathrm{A}$ but if at that time ECE is applied its $p_{\mathrm{f}}$ will be equal to the value at point B. Fig. (4) also indicates that the impact of ECE is proportional to the initial value of $p_{f}$. Therefore, the higher the $p_{f}$ is before the application of ECE the greater the reduction of $p_{f}$ is when ECE is applied.

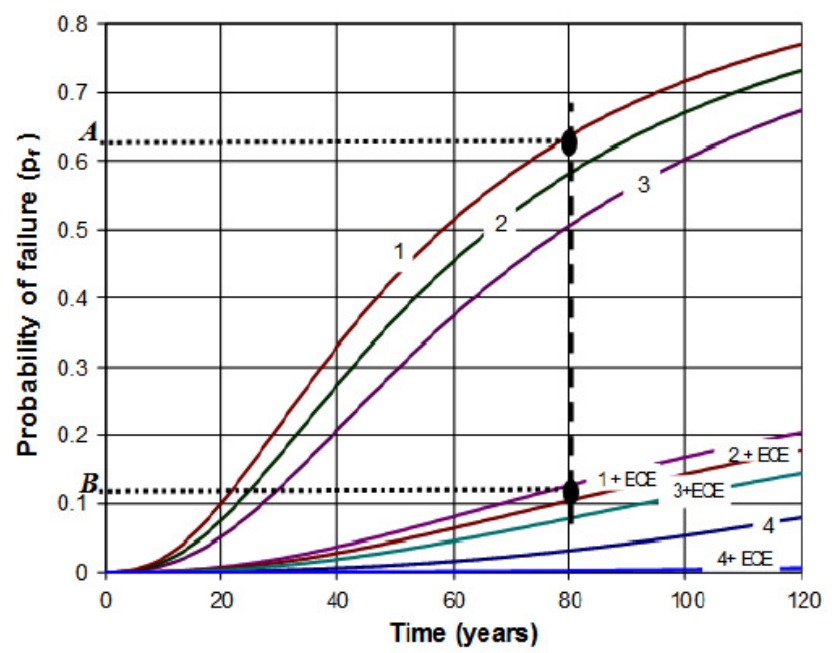

1: Plain concrete, 2: Silane, 3: Polyurethane sealer, 4: P-m coating, ECE: Electrochemical Chloride Extraction

Fig. (4). Effect of ECE on the probability of failure profiles on a 40 $\mathrm{mm}$ concrete cover (with and without surface treatments).

\subsection{Estimation of the $p_{f}$ at any Reference Time}

The equations of the profile curves $\left(\mathrm{p}_{\mathrm{f}}\right)$ can be obtained in MATLAB, using best fitting techniques. However due to the interaction of different PM measures, this is not a straight forward task. To overcome this and enable the calculation of the $\mathrm{p}_{\mathrm{f}}$ at any reference time under the action of PM (service life of PM) the following procedure which is depicted in Fig. (5) is used:

Step 1-2: At year 0, the $\mathrm{p}_{\mathrm{f} 0}$ (initial $\mathrm{p}_{\mathrm{f}}$ ) is assumed. From 0 to 5 year, the $\mathrm{p}_{\mathrm{f}}$ profile corresponding to the action applied at year 0 is used.

Step 2-3: At year 5, the $\mathrm{p}_{\mathrm{f5}}$ is matched to the corresponding $\mathrm{p}_{\mathrm{f}}$ of the profile of the selected PM $\left(\mathrm{PM}_{5}\right)$.

Step 3-4: Between 5 and 10 year the profile corresponding to the action applied at year 5 is used.
Step 5 - End of service life: The same process (step 2-3 and 3-4) is repeated for the remaining life of the bridge element.

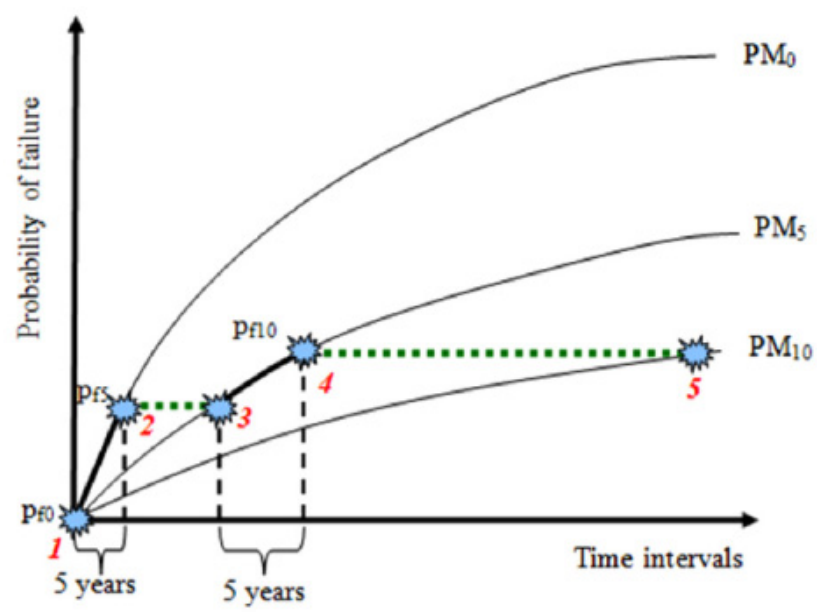

$\mathrm{p}_{\mathrm{fx}}$ : probability of failure at time $\mathrm{x}, \mathrm{PM}_{\mathrm{x}}$ : probability of failure profile of PM applied at time $\mathrm{x}$

Fig. (5). Estimation of $\mathrm{p}_{\mathrm{f}}$ at different time intervals.

\section{OPTIMUM PM STRATEGIES - A TWO STAGE GA METHODOLOGY}

Optimization is the art of producing the best alternative among a given set of options and constraints. In this study the aim is to develop a methodology to provide a tool for obtaining optimum PM strategies on RC bridges given the effectiveness of different PM measures.

Genetic algorithm (GA), an evolutionary technique, is been selected to implement this optimization. GA has many advantages against traditional optimization methods i.e. analytical optimization. These include the ability to search simultaneously in a population of points rather a single point, to use complex functions for the optimization problems, to incorporate a large number of parameters, etc [21].

The GA method was invented by John Holland [21] while Goldberg [6] was the first to solve engineering optimization problems using GA. Chikata et al. [22] was the first to apply GAs in the area of bridge management. Natsuaki et al. [23], Furuta et al. [8], Miyamoto et al. [24], Liu and Frangopol [4], Lee and Kim [10], Tantele and Onoufriou [25], Neves and Frangopol [26], Orcesi and Frangopol [11] used GA as part of bridge management systems for the optimization of maintenance or repair strategies and inspections schemes.

In this study a two-stage GA optimization approach was developed by the authors to identify optimum PM strategies. The proposed methodology integrates probabilistic modelling of PM effectiveness with the principles of GAs. The optimum preventative maintenance strategies are obtained through multi-objective optimization that combines minimum maintenance cost and acceptable probability of failure limits. The two-stage optimization methodology, as opposed to a single-stage approach, combined in this development 
results in more refined and reliable solutions. In particular, these solutions satisfy to a greater extent the defined objectives for minimizing the whole life cost and maintaining probability of failure below an acceptable level and can result in increased benefits in terms of safety and cost.

\subsection{Objective Function}

The aim of this study is to identify a PM strategy that will maintain the $\mathrm{p}_{\mathrm{f}}$ of an examined bridge element, under the actions of different PM measures, at minimum possible

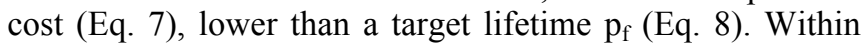
the context of this study, the probability of failure represents the probability of corrosion initiation on the top level of the steel reinforcement.

$$
\begin{aligned}
& F=\sum_{t=t}^{T-1} C_{P M_{t, j}} \rightarrow \min \text { cost } \\
& \begin{array}{c}
T-1 \\
t=t
\end{array} p_{f}\left(P M_{t, j}\right)<p_{f}(\text { target })
\end{aligned}
$$

where $\mathrm{F}$ is the total cost of PM measures; $\mathrm{C}_{\mathrm{PMt}, \mathrm{j}}$ is the cost of PM measure $j$ carried out in year $t ; j$ is the type of PM measure chosen for year $t ; p_{f}\left(P_{t, j}\right)$ is the probability of failure for PM measure $j$ carried out in year $t ; p_{f}$ (target) is the maximum acceptable value of $p_{f}$; $T$ is the expected service life of the bridge element (set here equal to 120 years); $t$ is the bridge element age (years) and t' is the present age of bridge element (set here equal to 0 ).

\subsection{Initial Population and Parameter Representation in the GA}

Different possible PM strategies are represented by arrays of parameters called chromosomes. Within a chromosome, each parameter, called gene, represents a PM action within the strategy. In this development, value (integer) encoding is used to represent the genes of the chromosomes since it offers the advantage of requiring less storage than the binary genetic algorithm. Every possible PM action, applied at a particular time during the life in the bridge, is represented by an integer number and consequently the PM plan is described as an array of integer numbers $\left(\mathrm{N}_{\mathrm{par}}\right)$ such as: $\mathrm{PM}$

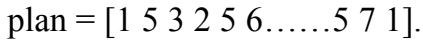

The PM actions (e.g. 1, 5, 3 etc.) will be applied in a given time interval. A random generator is used to generate the initial population ( $\mathrm{N}_{\text {ipop }}$ ) (Step 1 in GA part A, Fig. 6) of the $\mathrm{PM}$ action which consists of 48 chromosomes.

\subsection{Fitness, Selection and Mating Pool}

During each successive generation, each chromosome is tested based on the fitness function (Step 2 in GA part A, Fig. 6). This function (which is the same as the objective function) is evaluated independently for each chromosome by inserting the numerical values corresponding to its genes. The chromosomes are ranked based on their fitness scores and the top half is selected based on higher fitness (representing better solutions to the problem). However, the initial population is too large to undertake the whole process of the genetic algorithm. Haupt R and Haupt S [7] state that often only $50 \%$ of the initial population is kept and this is adopted here:
$N_{\text {pop }}=0.5 N_{\text {ipop }}$

The mating pool (parent's pool) contains the $\mathrm{N}_{\text {good }}$ chromosomes that are the fittest chromosomes from the earlier selected $\mathrm{N}_{\text {pop. }}$. A crossover rate $\left(\mathrm{X}_{\text {rate }}\right)$ is used to decide the number of selected chromosomes that will form the mating (parents) pool:

$N_{\text {good }}=X_{\text {rate }} N_{\text {pop }}$

High crossover rates introduce many new chromosomes into the population. On the other hand a low $\mathrm{X}_{\text {rate, }}$, does not do much exploring the population.

From the literature the crossover rate is often taken from the range $60 \%-100 \%$ [9]. The $\mathrm{X}_{\text {rate }}$ can be constant throughout the generations or vary from generation to generation [7]. Then a pair of parents is selected to produce offsprings using the roulette wheel selection [5] with rank weighting [7].

\subsection{Crossover and Mutation}

The offsprings are produced using the crossover operator (Step 3 in GA part A, Fig. 6). Crossover is inspired by the role of sexual reproduction in the evolution of biological organisms where the offsprings are formed by combining elements of existing solutions (e.g. DNA strands) in order to have some of the features of each parent. There are many possible ways to perform a crossover operation; in this study, single point crossover [9] is chosen. Crossover will result in the creation of two new offspring chromosomes.

The newly created offsprings can then be mutated (Step 4 in GA part A, Fig. 6). Mutation is a simple operator consisting of random alterations in the value of genes. Mutation is the only way to bring new genes to be tested into a population and avoid convergence to a local minimum. For this reason mutation is applied to the whole population (parent and offspring chromosome) to account also for mutation that parent chromosomes can be subjected to in their lifetime and enhance the chances in converging to optimum solution. A simple mutation for real value encoding is adopted which consists of randomly changing the value of a gene in the chromosome. The points to be mutated are selected randomly while the number of points that will be mutated depends on the mutation rate [7] as shown in Equation 11.

Number of points to be mutated $=\left(N_{\text {pop }} N_{\text {par }}\right) M_{\text {rate }}$

The mutation rate usually varies from $1 \%$ to $20 \%$. If the mutation rate is too high, the search becomes effectively random since a lot of random changes will occur with a lot of offsprings which do not resemble their parents. If the mutation rate is too low many useful genes will never be tested. As with the case of $X_{\text {rate }}, M_{\text {rate }}$ can be constant or vary during the GA process. However, it is not wise to perform mutation to already good solutions. For this reason elitism selection is often embedded [8] to enforce the preservation of the best chromosomes of the current generation to the next (Step 5 in GA part A, Fig. 6). With elitism, a number of good solutions are designated as elite solutions and are destined to propagate unchanged. Within the scope of this application two "parent" chromosomes with the least overall PM cost are not subjected to mutation. 
Two- stage GA

\section{methodology}

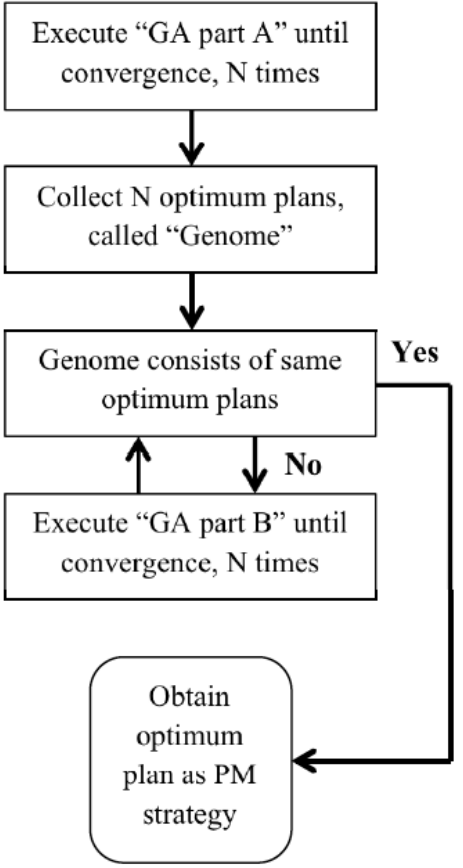

GA Part A / Part B

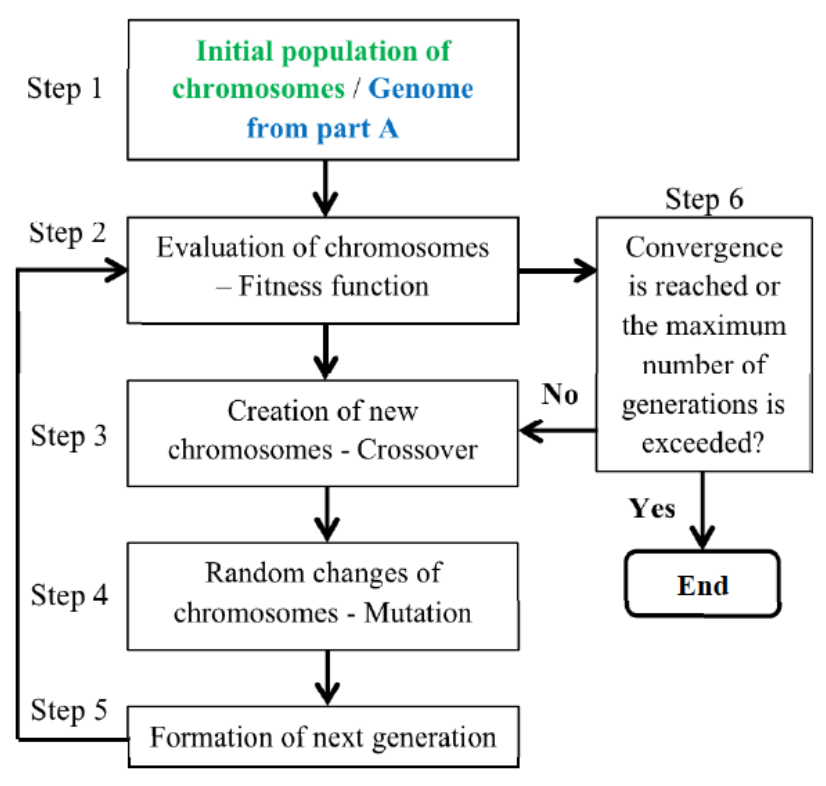

Fig. (6). Proposed two stage GA methodology.

Table 3. PM measures used in Case 1 and 2.

\begin{tabular}{|c|c|c|c|c|c|c|c|}
\hline $\begin{array}{c}\text { PM } \\
\text { Actions }\end{array}$ & $\begin{array}{c}\text { Do } \\
\text { nothing }\end{array}$ & $\begin{array}{c}\text { P-m } \\
\text { coating }\end{array}$ & Silane & Sealer & $\begin{array}{l}\text { Cathodic } \\
\text { protection }\end{array}$ & $\begin{array}{l}\text { Chloride } \\
\text { extraction }\end{array}$ & $\begin{array}{c}\text { Concrete } \\
\text { replacement }\end{array}$ \\
\hline Case 1 & $\checkmark$ & & & & & & $\checkmark$ \\
\hline Case 2 & $\checkmark$ & $\checkmark$ & $\checkmark$ & $\checkmark$ & $\checkmark$ & $\checkmark$ & $\checkmark$ \\
\hline
\end{tabular}

\subsection{Convergence}

The convergence in this study is reached when in the parent population the chromosomes are the same. Hence, in this case even when carry out crossover, there is no change in the genes and therefore one optimum solution is proposed (Step 6 in GA Part A, Fig. 6). The entire "GA Part A" process (Fig. 6) is repeated to obtain a number of optimum solutions and to select the solution that fits best the objective/fitness functions.

Unfortunately, the "GA Part A" may fail because of a convergence to an unacceptable local optimum. To overcome this limitation, an improved two-stage GA methodology (Part A + Part B), outlined in Fig. (6), is proposed. The purpose of the "GA Part B" is twofold: firstly, to aid the finding of the optimum solution and secondly, to ascertain whether there are flaws in the selection of key parameters of the GA process in order to revise them and achieve convergence more efficiently.

As Fig. (6) illustrates, "GA Part A" is executed and the collected optimum solutions from the genome which is treated as the initial population in "GA Part B" (Step 1 in GA Part B, Fig. 6). The simulations in "GA Part B" stop when all the chromosomes of the genome are the same, thus one optimum solution (optimum PM strategy) is proposed. The termination of the simulations is based on the logic that "optimum" parents (optimum solutions) cannot produce "more optimum" offspring (optimum solutions). For the implementation of the proposed methodology a computer program was developed using Visual Basic environment.

\section{NUMERICAL CASE STUDIES}

Two case studies are considered and the different measures used are presented in Table 3. Case 1 is a simple example that also serves as useful validation for the ad hoc developed Visual Basic program. The optimum plan for this case can also be identified manually and confirms the accuracy of the program. Case 2 was selected to combine a number of proactive and reactive PM measures to demonstrate the effective application of the programme and the outcome of the methodology when various PM options are available for selection.

Both of the examples examine a reinforced concrete beam with $40 \mathrm{~mm}$ concrete cover that is subjected to deicing salts. In each case the minimum cost of an optimum 
PM strategy and the corresponding probability of failure when the strategy is applied, are identified. Preventative maintenance is carried out at specified time intervals and can be either proactive or reactive. The interval for PM maintenance action is assumed to be five years so PM is applied after a principal inspection [27]. The bridge life (assumed 120 years) is divided into twenty-four, 5-year intervals. Proactive PM measures such as surface treatment measures, involve carrying out works before a problem arises. The reactive PM measures (i.e., concrete replacement, cathodic protection, chloride extraction) are applied when initiation of corrosion is observed (i.e., $p_{f}$ reach the target $p_{f}$ ). The effectiveness of PM measures is obtained from the probabilistic procedure introduced and explained in previous sections. The values for the various parameters involved in the probabilistic analysis are listed in Table 2 in Section 4. The parameters used in the GA methodology are given in Tables 46. In particular, Table 4 gives the discount rate, initial $\mathrm{p}_{\mathrm{f}}$, target $p_{f}$ and the service life of the bridge element utilized in this study.

Table 4. Parameters used for the case studies.

\begin{tabular}{|c|c|c|}
\hline Discount Rate & $3 \%$ & {$[28]$} \\
\hline Target $\mathrm{p}_{\mathrm{f}}$ & 0.1 & {$[29]$} \\
\hline Initial $\mathrm{p}_{\mathrm{f}}$ & 0 & \\
\hline $\begin{array}{c}\text { Service life of the } \\
\text { bridge element }\end{array}$ & 120 years & {$[29-31]$} \\
\hline
\end{tabular}

Table 5 presents the encoding representation used for the maintenance actions. As stated before, value (integer) encoding is used for the representation of genes (i.e., PM actions) of the chromosome (PM strategy). Since the interval for PM maintenance action is assumed to be five years the total genes of the chromosomes are 25 (120 years life of element). With seven possible options (PM) the possibilities are equal to $7^{25}$. Therefore with the addition of one more PM the combinations are dramatically increased from $7^{25}$ to $8^{25}$. From this, it is clear that a pure random search or identification of all possible combinations (event tree; [2]) it is not practical compared to GAs. Also, Table $\mathbf{5}$ shows the service life and the costs of PM measures used in the methodology [17, 3234] although some are approximate based on the literature, and some are assumed.

The whole life PM measures cost is the sum of all PM applications costs applied during the assumed service life, and are respectively discounted to the present value according to:

$C_{P M}=\sum_{i}^{j} \frac{C_{P M}(i)}{(1+r)^{t_{i}}}$

where $\mathrm{C}_{\mathrm{PM}}$ is the sum of the discounted cost of $\mathrm{j}^{\text {th }} \mathrm{PM}$ applications options $\left(P M_{(i)}\right)$ applied at time $\mathrm{t}_{\mathrm{i}}$; and $\mathrm{r}$ is a constant discount rate of money.

Table 6 gives the parameters of the genetic operators used for the GA methodology (Fig. 6). Selection method, crossover method and crossover rate were selected based on literature to achieve efficiency while satisfying the convergence requirements. Population size and the mutation rate are taken from a sensitivity study carried out by the authors [13].

Table 5. PM parameter representation for the GA.

\begin{tabular}{|c|c|c|c|}
\hline Maintenance action & $\begin{array}{c}\text { Genetic } \\
\text { code }\end{array}$ & Time (years) & Cost $\left(\boldsymbol{\epsilon} / \mathbf{m}^{2}\right)$ \\
\hline \hline Do nothing & 1 & N/A & N/A \\
\hline Silane & 2 & 5 & 4 \\
\hline Polyurethane sealer & 3 & 5 & 5 \\
\hline P-m coating & 4 & 10 & 30 \\
\hline Cathodic protection & 5 & As long as in & $\begin{array}{c}\text { Installation cost: } \\
\text { service }\end{array}$ \\
\hline $\begin{array}{c}\text { Electrochemical } \\
\text { chloride extraction }\end{array}$ & 6 & $\approx 6$ weeks & $70^{*}$ \\
\hline \begin{tabular}{c} 
Concrete replacement \\
\hline
\end{tabular} & 7 & N/A & 1940 \\
\hline
\end{tabular}

*the cost includes maintenance of the anodes, application of sealer and inspection costs for every 5 years.

\subsection{Case Study 1}

For this case study only two actions are considered, namely "Do nothing" and "Concrete replacement" (Table 3). By using the proposed two stage GA methodology (Fig. 6) an optimum plan is proposed after 8 generations, with a WLC (whole life costing) equal to $€ 2895.9 / \mathrm{m}^{2}$ (Fig. 7).

The optimum PM plan proposed by the GA methodology, showing the various actions selected at 5 year intervals, can be seen in Fig. (7). Every twenty years the option "Apply concrete replacement" was chosen since the target $p_{f}$ was reached at that time interval.

To visualize the element performance when this optimum maintenance plan is applied, the $\mathrm{p}_{\mathrm{f}}$ profile is plotted as a function of the bridge element age (Fig. 7). It can be observed that at no time frame the $\mathrm{p}_{\mathrm{f}}$ exceeds the target $\mathrm{p}_{\mathrm{f}}$ failure.

\subsection{Case Study 2}

In the second case study more measures were studied as it can be seen in Table 3. Proactive PM measures such as surface treatment and reactive measures such as cathodic protection and chloride extraction were examined. The optimum combination of measures as established by the GA methodology gives even lower cost $\left(€ 100.7 / \mathrm{m}^{2}\right.$; achieved at the $33^{\text {rd }}$ generation) in comparison with Case 1 (Fig. 7), showing that the methodology is able to identify more optimum strategies using a wide range of PM measures. 
Table 6. Parameters of the genetic operator.

\begin{tabular}{|c|c|c|}
\hline Parameter & Parameter value & Reference \\
\hline \hline Initial population & 48 & 48 \\
\hline Population size in every generation & Roulette wheel selection and elitism selection \\
\hline Selection method & Single point crossover & {$[7]$} \\
\hline Crossover method & Constant $100 \%$ & {$[4]$} \\
\hline Crossover rate, $\mathrm{X}_{\text {rate }}$ & Constant $6 \%$ & {$[24]$} \\
\hline Mutation rate, $\mathrm{M}_{\text {rate }}$ & Until convergence or 300 generations & \\
\hline Maximum generation & & \\
\hline
\end{tabular}

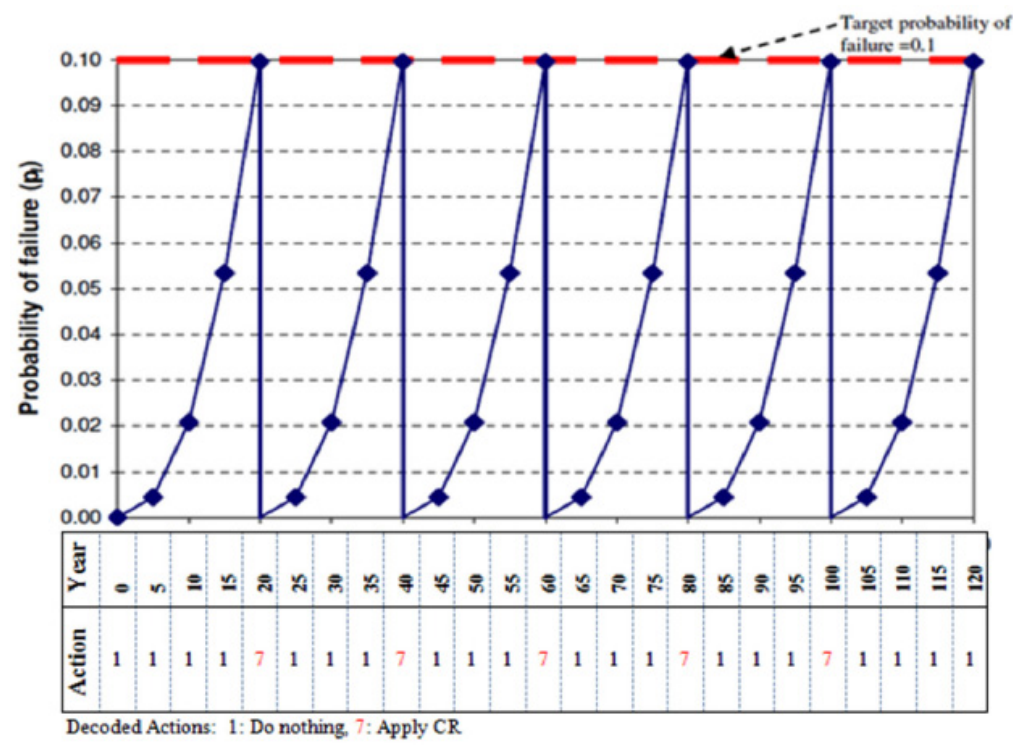

Fig. (7). Probability of failure profile for case 1 after application of the proposed strategy.

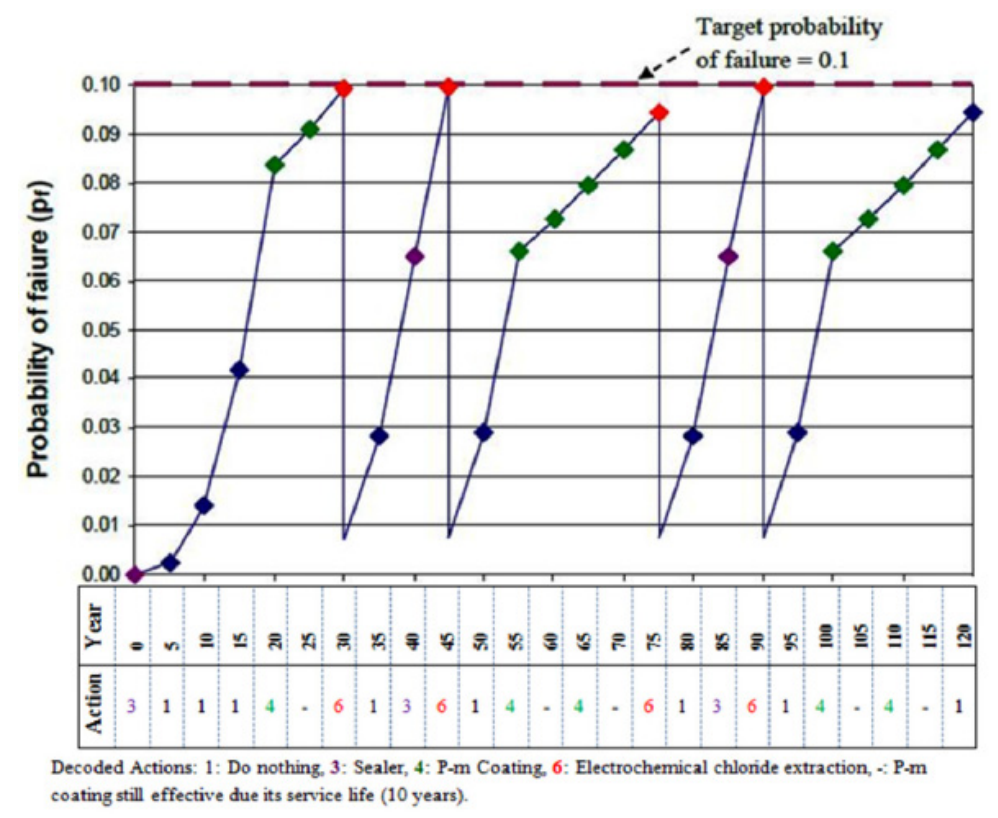

Fig. (8). Probability of failure profile for case 2 after application of the proposed strategy. 
The element performance when this recommended optimum PM plan is applied can also be seen in Fig. (8) which shows the $\mathrm{p}_{\mathrm{f}}$ profile versus time. At no time frame the $\mathrm{p}_{\mathrm{f}} \mathrm{ex}-$ ceeds the target $p_{f}$. Based on the set of input data the program chooses to utilize electrochemical chloride extraction rather than cathodic extraction or concrete replacement when critical concentration of chloride was expected on the rebar. This makes sense, since the use of electrochemical chloride extraction has a dramatic impact on the $p_{f}$ profile at little cost compared to the other reactive options. The application of PM measures is not the same throughout the lifetime of the element since the costs are discounted and cheaper solutions were sought at the beginning of the strategy ( $0-20$ years).

\section{CONCLUSION}

This paper presents two methodologies as part of a wider study by the authors that aims to develop optimum preventative maintenance (PM) strategies framework for RC bridges. The first methodology is a stochastic PM effectiveness methodology that provides a tool for relating and modelling the uncertainties associated with the effectiveness of different PM measures such as the large scatter and variability of field data. The limit state is set to satisfy the condition, that the chloride concentration at the surface of the steel reinforcement should not exceed a threshold value, so that the corrosion process is either delayed or prevented. The effectiveness of PM measures is represented by probability of failure $\left(\mathrm{p}_{\mathrm{f}}\right)$ profiles which indicate the violation of the limit state, i.e. the probability that corrosion initiation will occur at different times. Two types of PM are examined: proactive and reactive. Proactive PM measures such as surface treatments are applied to bridge members that are not affected by corrosion initiation where reactive PM measures such as chloride extraction are applied to members on which corrosion process has initiated. The probability profiles demonstrate that PM measures can delay/inhibit the deterioration mechanism and shift the time of corrosion initiation to a later time.

The second methodology uses the principles of Genetic Algorithms to combine and link the effectiveness of different PM measures with their cost in order to obtain optimum PM strategies. These optimum PM strategies give a suggested course of actions which maintains the lifetime $\mathrm{p}_{\mathrm{f}}$ of the examined element lower than the target lifetime $p_{f}$ and the whole life cost of the strategy as low as possible. Two case studies are presented to demonstrate the effective and successful application of the methodology, which are focusing mainly on the effects of different PM options on the optimum strategy solutions.

The combination of the two developed methodologies offers a valuable tool for engineers, enabling them to gain better understanding of the relative effectiveness of PM. As a result a more effective selection and application of PM measures can be achieved with the aim of maintaining the safety and performance of bridges at acceptable levels with the minimum possible cost. The methodologies although demonstrated on RC bridges, are generic and can be easily adapted for any deterioration mechanisms, structures or networks. The outcomes of these methodologies can benefit significantly authorities as potential end users, by keeping the safety requirements with the lowest associated cost.

\section{CONFLICT OF INTEREST}

The authors confirm that this article content has no conflict of interest.

\section{ACKNOWLEDGEMENTS}

The support of this research by the UK Highways Agency (HA) and Transport Research Laboratory TRL is gratefully acknowledged. The opinions and conclusion presented in this paper are those of the authors and do not necessarily reflect the view of the sponsoring organizations.

\section{REFERENCES}

[1] PIARC Committee on Road Bridges, "Towards an indicator of the health condition of bridges", World Road Association, 1996. [https://books.google.com.pk/books/about/Towards_an_indicator_o f_the_health_condi.html?id=-onMAAAACAAJ\&redir_esc=y]

[2] P.R. Vassie and C. Arya, "Selecting appropriate remedial measures for corroding concrete structures", In: Proceedings of the $4^{\text {th }}$ International Conference on Bridge Management 4; Inspection Maintenance, Assessment and Repair, London: Thomas Thelford Ltd, 2000, pp. 524-35.

[3] J.S. Kong and D.M. Frangopol, "Life-cycle reliability-based maintenance cost optimization of deteriorating structures with emphasis on bridges", Journal of Structural Engineering, vol. 129, no 6, pp. 818-28, 2003.

[4] M. Liu and D.M. Frangopol, "Optimal bridge maintenance planning based on probabilistic performance prediction", Engineering Structures, vol. 26, no. 7, pp. 991-1002, 2004.

[5] L. Davis, Handbook of Genetic Algorithms, Van Nostrand Reinold, New York, 1991.

[6] D. Goldberg, Genetic Algorithms in Search, Optimization, and machine learning, Addison- Wesley Publishing Company, INC, 1989.

[7] R. Haupt and S. Haupt, Practical Genetic Algorithms, John Wiley and Sons, Inc., USA, 1998.

[8] H. Furuta, M. Dogaki and N. Nakatsuka, "Optimal repair planning of existing bridges using genetic algorithm", In: Proceedings of the International Workshops on Optimal Performance of Civil Infrastructure Systems, ASCE, Portland, Oregon, 1997, pp. 116-26.

[9] A. Miyamoto, K. Kawamura and H. Nakamura, "Practical bridge management system in Japan (J-BMS)", In: Proceedings of the First International Conference on Bridge Maintenance, Safety and Management, IABMAS, Barcelona, Spain, CD - Rom Proceedings, 2002.

[10] C.K. Lee and S.K. Kim, "GA-based algorithm for selecting optimal repair and rehabilitation methods for reinforced concrete (RC) bridge decks", Automation in Construction, vol. 16, pp. 153-1564, 2007.

[11] A.D. Orcesi, and D.M. Frangopol, "Optimization of bridge maintenance strategies based on structural health monitoring information", Structural Safety, vol. 33, no. 1, pp. 26-41, 2011.

[12] M. Collepardi, A. Marcialis, and R. Turriziani, "The penetration of chloride ions in cement paste and concrete", Il Cemento, vol. 69, pp. 143-150 (in English and Italian), 1972.

[13] E.A. Tantele, T. Onoufriou, and M. Mulheron, "Effectiveness of preventative maintenance for reinforced concrete bridges - A stochastic approach", In: Proceedings of the $5^{\text {th }}$ International Conference on Bridge Management, 2005, pp. 443-451.

[14] N.R. Buenfeld, and J.Z. Zhang, "Chloride diffusion through surface-treated mortar specimens", Cement and Concrete Research, Elsevier Science Ltd, vol. 28, no. 5, pp. 665-674, 1998.

[15] G.G. Clemena, and D.R. Jackson, Cathodic Protection of Concrete Bridge Decks Using Titanium-mesh Anodes, Final report, Transportation Research Council, Virginia VTRC 00 R14, Virginia, 2000.

[16] S.R Sharp, G.G. Clemena, Y.P. Virmani, G.E. Stoner, and R.G. Kelly, "Electrochemical Chloride Extraction: Influence of Concrete Surface on Treatment", Final Report, FHWA-RD- 02-107, Virginia Transportation Research Council, 2002.

[17] P.D. Krauss, J.S. Lawler, K.A. Steiner, W. Janney, and Elstner Associates, Inc. "Guidelines for Selection of Bridge Deck Overlays, Sealers and Treatments", Report, National Cooperative highway 
research program (NCHRP), Transportation Research Board of the National Academies, Northbrook, Illinois, 2009.

[18] C.R. Middleton, and V. Hogg, "Review of Deterioration Models Used to Predict Corrosion in Reinforced Concrete Structures", Technical report, University of Cambridge, CUED/DSTRUCT/TR.173, 1998.

[19] M.K. Chryssanthopoulos, and G. Sterritt, "Integration of deterioration modelling and reliability assessment for reinforced concrete bridge structures", In: Proceedings of the $1^{\text {st }}$ ASRANet International Colloquium, CD-ROM, London, 2002.

[20] K.A.T. Vu, and M.G. Stewart, "Structural reliability of concrete bridges including improved chloride-induced corrosion models", Structural Safety, vol. 22, no. 4, pp. 313-33, 2000.

[21] J.H. Holland, Adaptation in Natural and Artificial Systems, University of Michigan Press, Ann. Arbor 1975.

[22] Y. Chikata, K. Tachibana, T. Kido, and T. Kobori, "A study on adopting the genetic algorithm to planning of bridge maintenance", Proceedings of Annual Conference of Japan Society of Civil Engineers, vol. 49, pp. 750-51, 1994.

[23] Y. Natsuaki, H. Furuta, S. Mukandai, and K. Yasuda, "Application of genetic algorithm to bridge construction management", In: $S U$ MANAFIPS '95: Proceedings of the International Symposium on Uncertainty Modelling and Analysis, Los Alamitos, CA, IEEE Computer Society Press, vol. 3, pp. 105-108, 1995.

[24] A. Miyamoto, K. Kawamura, and H. Nakamura, "Bridge management system and maintenance optimization for existing bridges", Computer Aided Civil and Infrastructure Engineering, vol. 15, no. 1, pp. 45-55, 2000.

[25] E.A. Tantele, and T. Onoufriou, "Optimization of life-cycle preventative maintenance strategies using genetic algorithm and bayesian updating”, In: The Proceedings IABMAS'10 - $5^{\text {th }}$ Interna- tional Conference on Bridge Maintenance, Safety and Management, SmartEN ITN Mini-Symposium, Philadelphia, Pennsylvania, USA, 2010, pp. 1594-1601, 11-15.

[26] L.C. Neves, and D.M. Frangopol, "Optimization of bridge maintenance actions considering combination of sources of information: inspections and expert judgment", In: The Proceedings of the Bridge Maintenance, Safety, Management and Life-Cycle Optimization, Taylor and Francis Group, London, England, 2010, pp. 374-379.

[27] Design Manuals for roads and bridges, BD 63/07: Highway Structures: Inspection and maintenance, vol. 3, section. 1, Inspection, HMSO, London, 2007

[28] H.M. Treasury, Green book, Appraisal and Evaluation in Central Government, TSO, Guidance London 2003.

[29] Basis of structural design, EN 1990, Eurocode, British Standards Institution, London, 2004

[30] Probabilistic model code, Part 1- Basis of design, Joint Committee on Structural safety, JCSS OSTL/DIA/VROU-10-11-2000, JCSS, 2000 .

[31] Design of concrete structures - Part 2: Bridges, EN 1997, Eurocode, British Standards Institution, London, 2007.

[32] Highways Agency, "Serviceable Life of Highway Structures and their Components", Final Report, Project Number 970530, 1999.

[33] Y.C. Liang, W. Zhang, and Y.Xi, "Strategic Evaluation of Different Topical Protection Systems for Bridge Decks and the Associated Life-Cycle Cost Analysis", Final Report no. CDOT-2010-6, Colorado Department of Transportation, 2010.

[34] R.E. Weyers, B.D. Prowell, M.M. Sprinkel, and M. Vorster, "Concrete Bridge Protection, Repair, and Rehabilitation Relative to Reinforcement Corrosion: a Methods Application Manual", Strategic Highway Research Program, SHRP-S-360, Washington, 1993.

Received: April 17, 2015

Revised: July 14, 2015

Accepted: July 16, 2015

(C) Tantele et al.; Licensee Bentham Open.

This is an open access article licensed under the terms of the (https://creativecommons.org/licenses/by/4.0/legalcode), which permits unrestricted, noncommercial use, distribution and reproduction in any medium, provided the work is properly cited. 